\title{
Трансформация элементного состава почвы еловых лесов в условиях долговременного атмосферного загрязнения
}

\section{Сухарева T.A.}

Институт проблем промышленной экологии Севера ФИЦ КНЦ РАН, Anamumbl, s.tat.a@mail.ru

\begin{abstract}
Аннотация. Выполнена оценка варьирования химического состава органогенного горизонта почв в лесных экосистемах, в том числе на территории Лапландского государственного природного биосферного заповедника в зоне влияния промышленных эмиссий комбината «Североникель» (г. Мончегорск, Мурманская обл.). Исследования проведены на стационарных пробных площадях на разном удалении от источника выбросов с учётом парцеллярной структуры биогеоценозов. За исследуемый период в органогенных горизонтах подкроновых пространств дефолиирующих лесов отмечено достоверное увеличение концентрации $\mathrm{Ca}$ и $\mathrm{Mg}$. Органогенные горизонты техногенных редколесий продолжают обедняться Сa, K, Mg, Mn. Анализ пространственно-временной динамики элементов питания и поллютантов с учётом парцеллярной структуры показал, что наиболее выражены изменения в почвах древесных парцелл еловых техногенных редколесий.

Ключевые слова: почва, органогенный горизонт, химические элементы, атмосферное загрязнение, еловые леса.
\end{abstract}

\section{Transformation of the elemental composition of soils of spruce forests in the conditions of long-term air pollution}

\section{Sukhareva T.A.}

Institute of Problems of Industrial Ecology of the North KSC RAS, Apatity, Murmansk region; s.tat.a@mail.ru

Abstract. The variation of the chemical composition of the organogenic soil horizon in forest ecosystems, including the Lapland State Natural Biosphere Reserve in the area of influence of industrial emissions of the «Severonikel» smelter (Monchegorsk, Murmansk region), has been estimated. The studies have been conducted in stationary sample areas at different distances from the emission source, taking into account the parcel structure of biogeocenoses. During the study period, a significant increase in the concentration of $\mathrm{Ca}$ and $\mathrm{Mg}$ has been registered in the organogenic horizons of the subcron spaces of defoliating forests. Organogenic horizons of technogenic woodlands continue to be depleted by $\mathrm{Ca}, \mathrm{K}, \mathrm{Mg}, \mathrm{Mn}$. The analysis of the spatial and temporal dynamics of nutrients and pollutants taking into account the parcel structure has showed that the most pronounced changes in the soils of tree parcels of sparse spruce forests.

Key words: soil, organogenic horizon, chemical elements, atmospheric pollution, spruce forests.

\section{Введение}

В процессе техногенной дигрессии происходит трансформация свойств почв. Кислотные осадки и загрязнение атмосферы соединениями тяжелых металлов могут приводить к значительным изменениям кислотности и питательного режима почв лесных биогеоценозов: повышению кислотности почв; возрастанию растворимости и мобильности тяжелых металлов и алюминия; снижению запасов элементов минерального питания (Ca, $\mathrm{K}, \mathrm{Mg}, \mathrm{Mn}$ и др.), которые могут замещаться в почвенном поглощающем комплексе ионами водорода, катионами тяжелых металлов и выноситься из корнеобитаемого пространства мобильными анионами (например, сульфатами) (Zoettl, Huettl, 1991). Согласно современным представлениям основным источником минерального питания растений с корневой стратегией питания является органогенный горизонт. Условия минерального питания определяют функционирование и устойчивость отдельных растений и лесных сообществ в целом. Органогенный горизонт рассматривается как эффективный биогеохимический барьер для тяжелых металлов, поступающих в экосистемы в результате атмосферного загрязнения (Лукина и др., 2008, Копцик, 2012, Лянгузова и др., 2016). Для оценки состояния лесных биогеоценозов в условиях аэротехногенного загрязнения большое значение приобретает изучение пространственно- 
временной динамики кислотности почв и содержание доступных соединений элементов в органогенном горизонте почв, особенно в условиях меняющихся факторов среды.

Лесные почвы, благодаря своим физическим и химическим свойствам, выступают как наиболее эффективные кратковременные и долговременные поглотители поллютантов. В почвенноэкологических исследованиях при оценке и контроле загрязнения почв тяжёлыми металлами широко применяется валовое содержание элемента, хотя почва способна связывать соединения металлов, переводя их в недоступные для растений формы. Поэтому для оценки поступления металлов из почвы в растения большое значение приобретают не столько валовые, сколько их доступные формы.

Цель исследования - оценка содержания доступных для растений соединений элементов в органогенном горизонте Al-Fe-подзолистых почв в процессе техногенной дигрессии еловых лесов, формирующихся в условиях долговременного техногенного загрязнения.

\section{Объекты и методы исследования}

Объекты исследования влияния воздушного промышленного загрязнения на элементный состав почв представляют собой стадии техногенно-пирогенной сукцессии ельников кустарничковозеленомошных в Мурманской области в окрестностях комбината «Североникель». Почвы в районе исследования представлены Al-Fe-гумусовыми подзолами, развитыми на ледниковых моренных песчаных отложениях (Переверзев, 2011). В современной классификации (Классификация..., 1997) подзолы, имеющие профиль О-Е-ВН-С, выделяются на уровне типа и входят в отдел альфегумусовых почв ствола постлитогенных почв (Переверзев, 2007).

$\mathrm{B}$ настоящее время объем атмосферных выбросов $\mathrm{SO}_{2}$ и $\mathrm{Ni}$ сократился более чем в 5 раз, $\mathrm{Cu}$ - почти в 3 раза по сравнению с уровнем начала 90-гг. XX в. (Sukhareva, Lukina, 2014).

Обследованы постоянные пробные площади по градиенту промышленного загрязнения в еловых лесах $(7,28,31,62$ км от источника атмосферных выбросов), соответствующих основным стадиям техногенной дигрессии. Фоновая территория была выбрана на значительном удалении от комбината (более 160 км).

Отбор образцов почв проводили в пятикратной повторности в межкроновых и подкроновых пространствах. Для еловых лесов выделены две основные парцеллы древесная (еловая кустарничковая) и межкроновая (кустарничково-зеленомошная и кустарничковая). Почвенные образцы высушивали при комнатной температуре, а затем просеивали. Аналитической обработке подвергали мелкозем (фракция < 1.0 мм).

Химический анализ выполнен согласно общепринятым методам (Аринушкина, 1970). Для определения концентрации доступных соединений элементов питания образцы почв обрабатывали $1 \mathrm{M} \mathrm{CH}_{3} \mathrm{COONH}_{4}(\mathrm{pH}=4.65)$. Для органогенных горизонтов использовали те же соотношения почвы и вытеснителя, что и при определении $\mathrm{pH}$ для минеральных горизонтов $-1: 10$. Содержание металлов определяли методом атомно-абсорбционной спектрофотометрии, содержание $\mathrm{P}$ - фотоколориметрическим методом по интенсивности окраски фосфорно-молибденового комплекса (метод Лоури-Лопеса), S - турбидиметрическим методом. Для сравнения химического состава хвои древесных растений в различные периоды отбора проводили однофакторный непараметрический анализ Kruskal-Wallis ANOVA (StatSoft Inc., 2010).

\section{Результаты}

Фоновые условия. В еловых лесах на северном пределе распространения органогенный горизонт является основным источником питания растений. Преобладающими среди доступных соединений элементов в этих горизонтах почв еловых лесов являются соединения кальция (табл. 1, 2). Выявляются межпарцеллярные различия в содержании доступных соединений элементов в органогенных горизонтах почв. Наиболее высоким содержанием доступных соединений кальция характеризуются органогенные горизонты почв еловых парцелл (подкроновое пространство). Одной из возможных причин, объясняющих этот факт, является состав опадающих ассимилирующих органов. В опадающей хвое ели отмечаются значительные концентрации кальция - до 1.5 г/кг (Манаков, Никонов, 1981). Кустарнички рода Vaccinium являются кальцефагами (Ingestad, 1973), листья вороники также отличает- 
ся высоким уровнем аккумуляции этого элемента (до 1.1 г/кг) (Лукина, Никонов, 1998). Как правило, в подкроновых пространствах кустарнички доминируют в напочвенном покрове, и их опад может, наряду с опадом хвои, определять состав органогенных горизонтов.

Таблица 1. Элементный состав органогенного горизонта почвы $\left(\mathrm{A}_{0}\right)$ подкронового пространства (древесная парцелла) еловых лесов на разных стадиях техногенной дигрессии, мг/кг.

Table 1. Elemental composition of the organogenic soil horizon $\left(\mathrm{A}_{0}\right)$ of the subsurface (woody parcel) of spruce forests at different stages of technogenic digression, $\mathrm{mg} / \mathrm{kg}$.

\begin{tabular}{|c|c|c|c|c|c|}
\hline \multirow{2}{*}{ Элемент } & \multicolumn{5}{|c|}{ Стадия техногенной дигрессии, км } \\
\hline & $\Phi, 167$ & Д1, 62 & Д2, 31* & Д3, 28 & $\mathrm{P}, 7$ \\
\hline $\mathrm{Ca}$ & $\frac{1543 \pm 320}{3678 \pm 570}$ & $\frac{3560 \pm 532}{3102 \pm 349}$ & $\frac{1951 \pm 247}{2657 \pm 292}$ & $\frac{1489 \pm 167}{2012 \pm 255}$ & $\frac{1040 \pm 261}{492 \pm 56}$ \\
\hline $\mathrm{K}$ & $\frac{1048 \pm 105}{1286 \pm 122}$ & $\frac{844 \pm 159}{861 \pm 102}$ & $\frac{929 \pm 173}{683 \pm 71}$ & $\frac{553 \pm 88}{486 \pm 65}$ & $\frac{278 \pm 5}{288 \pm 21}$ \\
\hline $\mathrm{P}$ & $\frac{306 \pm 21}{357 \pm 45}$ & $\frac{252 \pm 88}{201 \pm 32}$ & $\frac{138 \pm 42}{66 \pm 8}$ & $\frac{61 \pm 8}{66 \pm 24}$ & $\frac{36 \pm 5}{38 \pm 4}$ \\
\hline $\mathrm{Mg}$ & $\frac{206 \pm 34}{393 \pm 50}$ & $\frac{349 \pm 46}{416 \pm 29}$ & $\frac{227 \pm 31}{305 \pm 28}$ & $\frac{189 \pm 26}{238 \pm 26}$ & $\frac{165 \pm 34}{87 \pm 16}$ \\
\hline $\mathrm{S}$ & $\frac{79 \pm 11}{140 \pm 14}$ & $\frac{198 \pm 31}{240 \pm 46}$ & $\frac{146 \pm 9}{125 \pm 7}$ & $\frac{64 \pm 8}{80 \pm 14}$ & $\frac{195 \pm 11}{103 \pm 17}$ \\
\hline $\mathrm{Al}$ & $\frac{\text { H.O. }}{45 \pm 5}$ & $\frac{86 \pm 23}{158 \pm 20}$ & $\frac{929 \pm 173}{683 \pm 71}$ & $\frac{177 \pm 29}{220 \pm 47}$ & $\frac{550 \pm 99}{480 \pm 73}$ \\
\hline
\end{tabular}

Примечание. Здесь и в таблице 2 - над чертой данные 1992 г., под чертой - 2007 г., н.о. - не определяли; * - Лапландский государственный природный биосферный заповедник. Ф - фон; Д - дефолирующие леса, P-редколесье.

Таблица 2. Элементный состав органогенного горизонта почвы $\left(\mathrm{A}_{0}\right)$ межкронового пространства (кустарничковая парцелла) еловых лесов на разных стадиях техногенной дигрессии, мг/кг.

Table 2. The elemental composition of organogenic soil horizon $\left(\mathrm{A}_{0}\right)$ micronovae space (parcel shrub) spruce forests at different stages of technogenic digression, $\mathrm{mg} / \mathrm{kg}$.

\begin{tabular}{|c|c|c|c|c|c|}
\hline \multirow{2}{*}{ Элемент } & \multicolumn{5}{|c|}{ Стадия техногенной дигрессии, км } \\
\hline & $\Phi, 167$ & Д1, 62 & Д2,31* & Д3, 28 & $\mathrm{P}, 7$ \\
\hline $\mathrm{Ca}$ & $\frac{1586}{752 \pm 333}$ & $\frac{2546 \pm 201}{1771 \pm 320}$ & $\frac{1890 \pm 204}{1818 \pm 179}$ & $\frac{2430 \pm 124}{2036 \pm 446}$ & $\frac{2676 \pm 205}{959 \pm 246}$ \\
\hline $\mathrm{K}$ & $\frac{1349}{462 \pm 211}$ & $\frac{643 \pm 97}{760 \pm 85}$ & $\frac{722 \pm 173}{788 \pm 47}$ & $\frac{1088 \pm 43}{905 \pm 290}$ & $\frac{346 \pm 29}{228 \pm 48}$ \\
\hline $\mathrm{P}$ & $\frac{278}{120 \pm 33}$ & $\frac{92 \pm 32}{140 \pm 30}$ & $\frac{97 \pm 19}{120 \pm 21}$ & $\frac{159 \pm 18}{65 \pm 7}$ & $\frac{60 \pm 5}{47 \pm 19}$ \\
\hline $\mathrm{Mg}$ & $2 \frac{330}{227 \pm 63}$ & $\frac{453 \pm 54}{404 \pm 56}$ & $\frac{253 \pm 35}{278 \pm 14}$ & $\frac{382 \pm 13}{326 \pm 87}$ & $\frac{333 \pm 5}{162 \pm 57}$ \\
\hline $\mathrm{S}$ & $\frac{85}{66 \pm 17}$ & $\frac{139 \pm 32}{164 \pm 15}$ & $\frac{119 \pm 13}{131 \pm 4}$ & $\frac{181 \pm 11}{124 \pm 43}$ & $\frac{117 \pm 12}{75 \pm 17}$ \\
\hline $\mathrm{Al}$ & $2 \frac{\text { H.O. }}{264 \pm 75}$ & $\frac{51 \pm 13}{222 \pm 75}$ & $\frac{339 \pm 76}{227 \pm 39}$ & $\frac{143 \pm 29}{333 \pm 47}$ & $\frac{125 \pm 19}{503 \pm 179}$ \\
\hline
\end{tabular}

Более высокие содержания доступных соединений $\mathrm{Mn}, \mathrm{Zn}, \mathrm{Ni}, \mathrm{Cu}$ в органогенных горизонтах почв еловых парцелл могут определяться смывом и выщелачиванием из стволов и крон (Лукина, Никонов, 1998).

Дефолиирующие леса и техногенные редколесья. В органогенных горизонтах почв подкроновых пространств дефолиирующих лесов наблюдается снижение содержания доступных для растений соединений $\mathrm{Ca}, \mathrm{Mg}, \mathrm{K}, \mathrm{P}$ и увеличение содержания Al по сравнению с фоном. Особенно значительное возрастание содержания обменного Al наблюдается на стадии массового выпадения зеленых мхов, что, возможно, связано с высокой концентрацией этого элемента в опаде мхов. Сниже- 


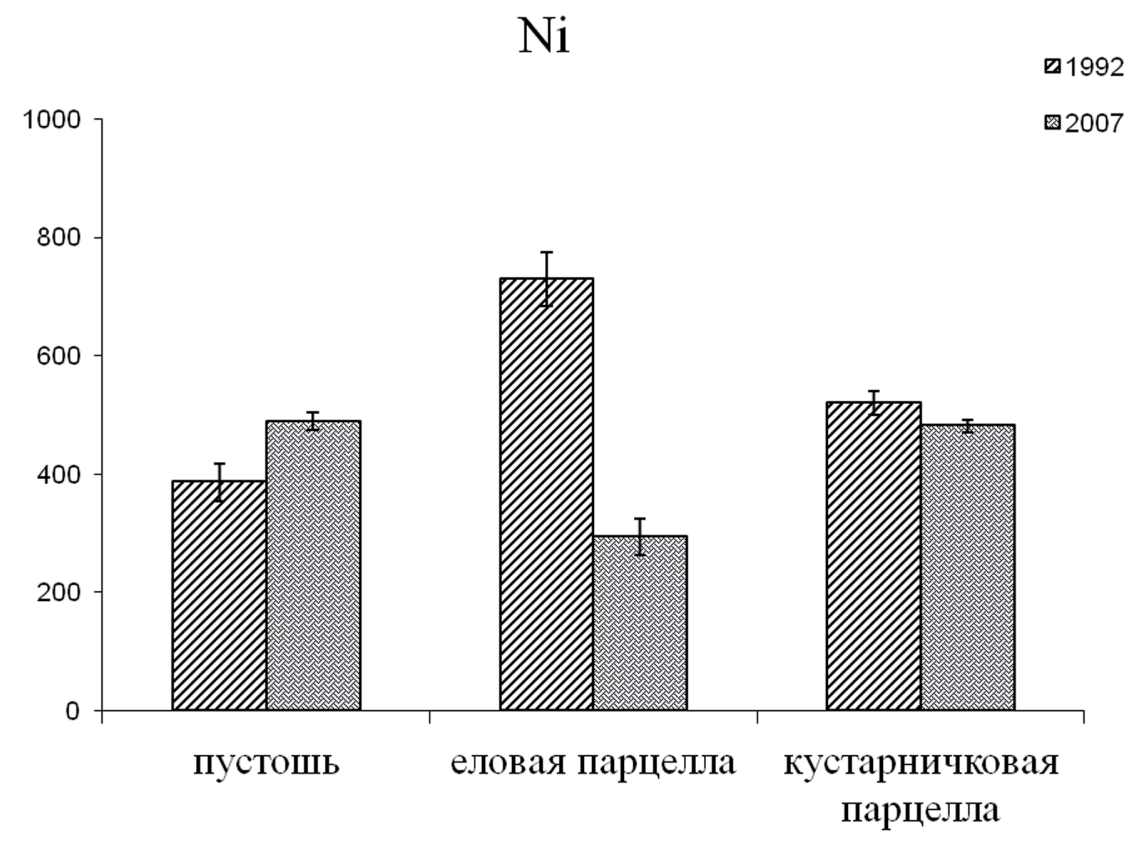

Рис. 1. Динамика содержания никеля в органогенном горизонте почв техногенных еловых редколесий в различных парцеллах, мг/кг.

Fig. 1. Dynamics of nickel content in the organogenic horizon of soils of sparse spruce forests in various parcels, $\mathrm{mg} / \mathrm{kg}$.

ние содержания основных катионов в органогенных горизонтах почв являются следствием катионообменных реакций в почвенном поглощающем комплексе: основные катионы вытесняются «кислыми» ионами водорода и алюминия. Кроме того, хвоя ели и ассимилирующие органы кустарничков значительно обедняются Са и $\mathrm{Mg}$, что также может являться причиной снижения содержания доступных соединений этих элементов в органогенных горизонтах почв (Лукина, Никонов, 1998). На данной стадии техногенной дирессии выявлено снижение содержания Mn и Zn (Сухарева, 2013), что обусловлено выносом этих элементов из органогенного горизонта в результате интенсификации потока кислотообразующих веществ из атмосферы. Другой причиной может быть уменьшение содержания этих элементов в растительном опаде. Пониженные содержания Р также связаны с их активным вымыванием из подстилки. Несмотря на значительное поступление соединений S с атмосферными выпадениями и интенсивным вымыванием их из крон деревьев, содержание доступных для растений соединений $\mathrm{S}$ в органогенных горизонтах не увеличивается. Это можно объяснить высокой миграционной способностью этого элемента. В почвенных водах фиксируется резкое возрастание концентраций сульфатов, которые способствуют миграции основных катионов (Лукина, Никонов, 1998).

В органогенных горизонтах почв кустарничково-зеленомошных парцелл (межкроновое пространство), которые трансформируются в условиях загрязнения в кустарничковые, в целом наблюдаются сходные с еловыми парцеллами изменения. Однако эти носят не столь ярко выраженный характер. Вероятно, это связано с формированием относительно устойчивого растительного покрова.

В органогенных горизонтах почв еловых парцелл техногенных редколесий наблюдаются сходные с дефолиирующими лесами тенденции изменения содержания подвижных соединений элементов в почвах. Запасы элементов питания в органогенных горизонтах почв техногенного редколесья не могут компенсироваться из-за уменьшения количества растительного опада и содержания органического вещества.

В органогенных горизонтах почв кустарничковых парцелл техногенного редколесья наблюдаются парцеллярные различия в содержании подвижных соединений элементов: в органогенных горизонтах почв кустарничковых парцелл обнаруживаются повышенные по сравнению с еловыми парцеллами содержания Са и $\mathrm{Mg}$ (табл. 2).

Сравнительная оценка микроэлементного состава, выполненная нами ранее на тех же стационарных площадках показала, что, несмотря на снижение объёмов выбросов, в почве сохраняются 
высокие концентрации элементов-загрязнителей $(\mathrm{Ni}, \mathrm{Cu}, \mathrm{Fe})$. В большинстве случаев их содержание остаётся либо сопоставимым с уровнем 1992 года, либо их концентрации даже возрастают (Сухарева, 2013). И только в почве еловых редколесий, содержания никеля достоверно (p<0.05) снижается в почвах древесных парцелл (рис. 1).

\section{Заключение}

В процессе техногенной дигрессии лесов элементный состав органогенных горизонтов почвы, являющегося основными источниками минерального питания растений, трансформируется. Почва обедняется важнейшими минеральными элементами - $\mathrm{Ca}, \mathrm{Mg}, \mathrm{Mn}, \mathrm{Zn}, \mathrm{K}, \mathrm{P}$, необходимыми для поддержания сбалансированного минерального состава растений и соответственно нормального функционирования растительного организма, а значит, и лесного фитоценоза в целом. На фоне снижения атмосферной нагрузки на лесные экосистемы устойчивой тенденции к улучшению состояния почв не выявлено.

Исследованиепроводилось при финансовой поддержкетемы НИР АААА-А1 8-118021490070-5 и гранта РФФИ 18-05-60142_Арктика.

\section{Литература}

1. Аринушкина Е.В. Руководство по химическому анализу почв. М. Изд-во: МУ. 1970. 488 с.

2. Классификация почв России. М. Изд-во: Почв. ин-т им. Докучаева. 1997. 235 с.

3. Копцик Г.Н. Трансформация и устойчивость почв лесных экосистем под воздействием атмосферного загрязнения. Автореф. дис. ... докт. биол. н. М. 2012. 46 с.

4. Лукина Н.В., Полянская Л.М., Орлова М.А. Питательный режим почв северотаежных лесов. М. Изд-во: Наука. 2008. 342 с.

5. Лукина Н.В., Никонов В.В. Питательный режим лесов северной тайги: природные и техногенные аспекты. Апатиты. Изд-во: КНЦ РАН. 1998. 316 с.

6. Лянгузова И.В., Гольдвирт Д.К., Фадеева И.К. Пространственно-временная динамика загрязнения AlFе-гумусового подзола в зоне влияния комбината цветной металлургии // Почвоведение. 2016. № 10. C. $1261-1276$.

7. Манаков К.Н., Никонов В.В. Биологический круговорот минеральных элементов и почвообразование в ельниках Крайнего Севера. Л. Изд-во: Наука. 1981. 196 с.

8. Переверзев В.Н. Зональные особенности альфегумусового почвообразования на моренных породах Кольского полуострова // Почвоведение. 2007. № 1. С. 5-11.

9. Переверзев В.Н. Почвообразование в лесной зоне Кольского полуострова // Вестник Кольского НЦ РАН, 2011. № 2. C. 74-82.

10. Сухарева Т.А. Пространственно-временная динамика микроэлементного состава хвойных деревьев и почвы в условиях промышленного загрязнения // Известия высших учебных заведений. Лесной журнал. № 6. 2013. C. 19-28.

11. Ingestad T. Mineral nutrient requirements of Vaccinium vitis-idaea and Vaccinium myrtillus // Physiologia Plantarum. 1973. V. 29. P. 239-246.

12. Sukhareva T.A., Lukina N.V. Mineral composition of assimilative organs of conifers after reduction of atmospheric pollution in the Kola Peninsula // Russian Journal of Ecology. 2014. V. 45. №. 2. P. 95-102.

13. Zoettl H.W., Huettl R.F. (ed.) Management of nutrition in forests under stress. Dordrecht: Kluwer, 1991. 668 p. 